\title{
A Common Building Block for the Syntheses of Amorfrutin and Cajaninstilbene Acid Libraries toward Efficient Binding with Peroxisome Proliferator-Activated Receptors
}

\author{
Indrapal S. Aidhen, ${ }^{*}{ }^{\dagger}$ Ramesh Mukkamala, ${ }^{\dagger}$ Christopher Weidner, ${ }^{\ddagger}$ and Sascha Sauer ${ }^{*} \ddagger$ \\ ${ }^{\dagger}$ Department of Chemistry, Indian Institute of Technology Madras, Chennai 600036, India \\ ¥Otto-Warburg Laboratory, Max-Planck-Institute for Molecular Genetics, Ihnestrasse 63-73, 14195 Berlin, Germany
}

Supporting Information

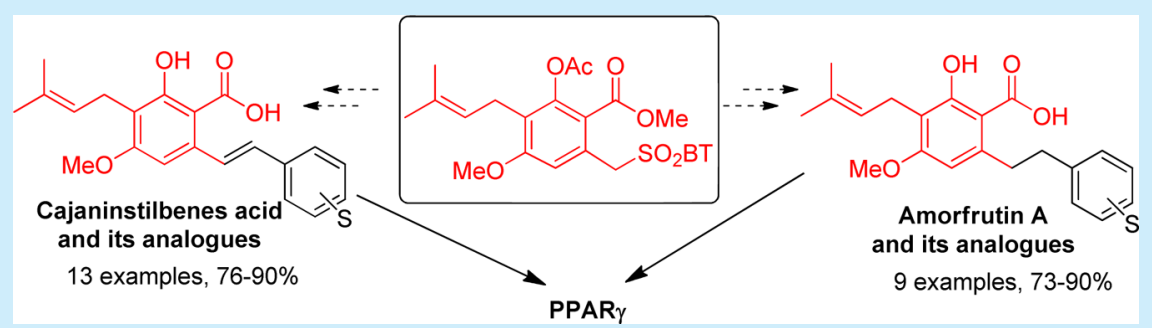

ABSTRACT: A common building block for the synthesis of amorfrutin and cajaninstilbene acid derivatives has been developed. The library of synthesized compounds has enabled identification of new nontoxic ligands of peroxisome proliferator-activated receptors (PPAR) and potential inhibitors of the transcriptional corepressor protein NCoR. The biological data holds promise in identification of new potential leads for the antidiabetic drug discovery process.

$\mathrm{T}^{\mathrm{h}}$ he peroxisome proliferator-activated receptors alpha, beta/delta, and gamma $(\operatorname{PPAR} \alpha, \operatorname{PPAR} \beta / \delta$, and $\operatorname{PPAR} \gamma)$ are important transcriptional regulators of the nuclear receptor family. ${ }^{1}$ These nuclear receptors like other generegulating enzymes such as chromatin modifiers ${ }^{2}$ are highly relevant drug targets, in particular for metabolic diseases. ${ }^{3}$ Amorfrutin A (1), ${ }^{4}$ a member of the so far largely unexplored isoprenoid-substituted benzoic acid derivatives, has been isolated from the two dietary legumes Glycyrrhiza foetida (licorice) and Amorpha fruticosa. ${ }^{5}$ Recently, it was shown that the naturally occurring amorfrutins $\mathrm{A}$ and $\mathrm{B}$ exert strong antidiabetic and lipid-lowering effects in vivo. ${ }^{5,6}$ The physiological effects of natural amorfrutins appeared to be mainly mediated by highly selective activation of PPAR $\gamma$ due to inhibited interaction with the nuclear receptor corepressor (NCoR) protein. ${ }^{7}$ In a number of preclinical tests, amorfrutin A and $\mathrm{B}$ did not show any side effects known from strong PPAR $\gamma$ targeting drugs of the thiazolidinedione family. ${ }^{5,6}$ However, nature only offers a very limited pool of amorfrutin structures, and rather low amounts of amorfrutins were found in relatively uncommon plants. ${ }^{8}$ So far, no systemic endeavors have been made to tailor synthetic routes for these promising natural products.

In general, hydroxy-substituted stilbenes $2^{9}$ display beneficial biological activities encompassing various therapeutic areas. For example, the stilbenoid 3 , known as cajaninstilbene acid, ${ }^{10}$ has shown strong antioxidant activity (Figure 1). ${ }^{11}$

The synthesis of prenyl-substituted bibenzyl derivative 1 usually applies the following protocols for $\mathrm{C}-\mathrm{C}$ bond formation between two benzyl residues: (a) Wittig reaction

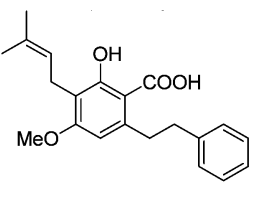

(1)

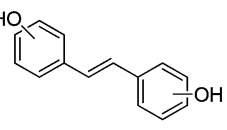

(2)

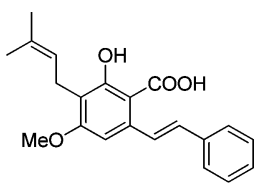

(3)
Figure 1. Amorfrutin A (1), stilbenoids (2), and cajaninstilbene acid (3).

followed by hydrogenation, ${ }^{12}$ (b) benzylic metalation followed by alkylation, ${ }^{13}$ (c) Sonogashira coupling for coupling of aryltriflate with phenyl-acetylene. ${ }^{5}$ A recent biomimetic approach uses 2,2,6-trimethyl-4H-1,3-dioxin-4-one as starting material to synthesize amorfrutin A through decarboxylative prenylation, migration, and aromatization sequence. ${ }^{14}$ Alternatively, amorfrutin A can be produced by tandem Michael additionintramolecular Claisen condensation followed by oxidative aromatization. ${ }^{15}$ The synthesis of prenylated stilbenoid 3 is currently based on the Horner-Wadsworth-Emmons approach for the $\mathrm{C}-\mathrm{C}$ double bond formation ${ }^{16}$ or alternatively olefination of aromatic aldehydes with thiophthalides. ${ }^{17}$ The relatively narrow substrate scope in the available methods, for both prenylated bibenzyl $\mathbf{1}$ and stilbenoid 3, was the key limiting factor in efficiently developing analogues.

Given the great biomedical potential of compounds $\mathbf{1}$ and 3, the need to develop a general efficient strategy for generating

Received: October 30, 2014

Published: December 23, 2014 
libraries from a common building block became urgent. Therefore, we designed the common building block 4 for the synthesis of both types of compounds (1 and 3) to achieve efficient synthesis of prenylated bibenzyls 5 and prenylated stilbenoids 6, containing a functionalized aromatic ring (Figure 2). ${ }^{18}$ This building block 4 enables synthesis of bibenzyl

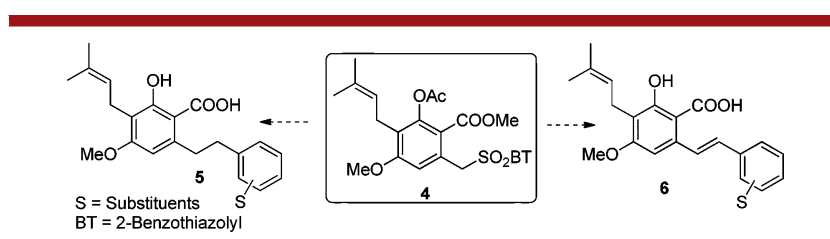

Figure 2. Common building block for prenylated bibenzyls and stilbenoids.

derivatives $\mathbf{5}$ through a sequence comprising benzylation with various substituted benzyl bromides, followed by desulfonylation and hydrolysis, whereas synthesis of $\mathbf{6}$ involves Julia olefination with various substituted aromatic aldehydes, followed by hydrolysis.

The synthesis of the common building block $4^{18}$ is presented in Scheme 1. Starting with $7,{ }^{19}$ thio-alkylation of 2-mercapto-

Scheme 1. Synthesis of the Key Building Block (4)

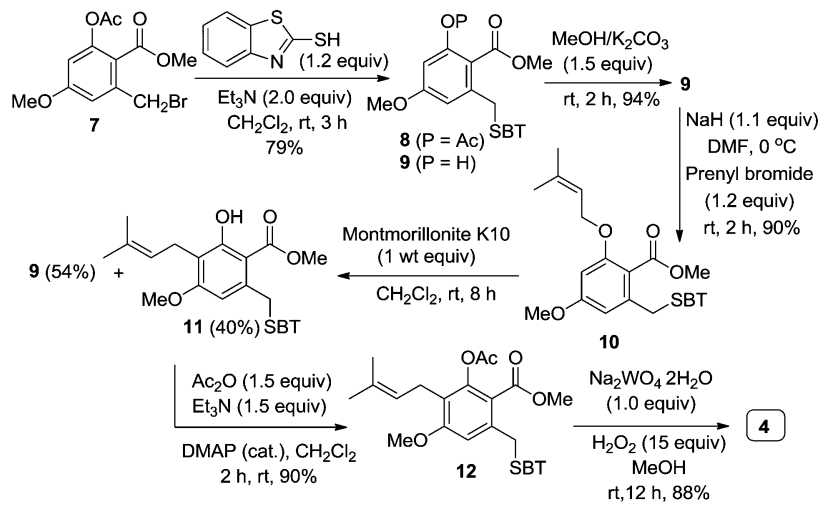

benzothiazole with the bromide 7 in dichloromethane using triethylamine as a base resulted in the formation of the sulfide 8 in good yield (79\%). For installation of the prenyl moiety on the aromatic ring, compound $\mathbf{8}$ was deacetylated and a procedure reported by Fürstner and $\mathrm{Gastner}^{20}$ for $C$ prenylation was applied on the phenolic compound 9. The reaction using sodium hydride as the base and prenyl bromide as the electrophile in toluene at $35^{\circ} \mathrm{C}$ was very sluggish and generated very low yield of the desired $C$-prenylated compound $11(15 \%)$, whereas the major product under these conditions was the $O$-prenylated compound 10 in $60 \%$ yield. These two compounds were easily separable using column chromatography over silica gel. In order to improve the yield of desired compound 11, we relied on rearrangement of the O-prenyl ether 10 to ortho-prenyl phenol 11. To achieve this, the $O$ prenylated product $\mathbf{1 0}$ was initially obtained in high yield (90\%) using DMF as a solvent and subjected to rearrangement. Among various possible reagents, use of Montmorillonite $\mathrm{K} 10^{21}$ led to the desired $C$-prenylated product 11 in modest yield $(40 \%)$. Although the major side product was the deprenylated compound 9 , the cyclic sequence $(\mathbf{9} \rightarrow \mathbf{1 0} \rightarrow$ 11) ensured no loss of material and assured regular supplies of compound 11. Acetylation of compound 11 and oxidation of the sulfide 12 with $30 \% \mathrm{H}_{2} \mathrm{O}_{2} / \mathrm{Na}_{2} \mathrm{WO}_{4} \cdot 2 \mathrm{H}_{2} \mathrm{O}$ in methanol furnished the desired building block $\mathbf{4}$ in good yield (88\%), as a white crystalline solid (Scheme 1).

Besides the NMR spectral analysis, the structure and position of the prenyl moiety in sulfone $\mathbf{4}$ was confirmed unambiguously using single-crystal X-ray diffraction analysis (see Supporting Information 1). ${ }^{22}$

As projected in the conceived strategy for substituted prenylated stilbenoids 6 , various substituted aromatic aldehydes 13a-131 were now subjected to modified Julia olefination reaction with building block 4 using sodium hydride as the base for initial generation of carbanion in DMF as the solvent. Functionalized stilbenes $\mathbf{1 4 a}-\mathbf{1 4 1}$ were obtained in good yields $(62-83 \%)$, as the $E$-isomer only, which was confirmed by the vicinal coupling constant value $\left({ }^{3} \mathrm{JH}_{\mathrm{HH}}=15.5-16.5 \mathrm{~Hz}\right)$ between the olefinic protons in their ${ }^{1} \mathrm{H}$ NMR spectrum (Scheme 2).

Scheme 2. Synthesis of Cajaninstilbenes Acid and Its Analogues (15a-151)

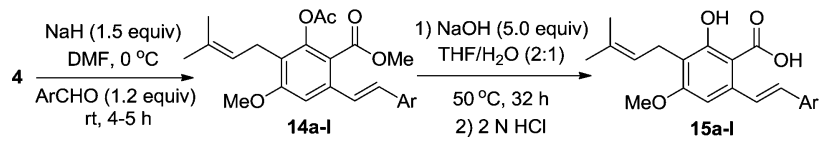

The acetate and methyl ester protections in stilbenes $14 a-141$ were conveniently removed by using $\mathrm{NaOH} / \mathrm{H}_{2} \mathrm{O} / \mathrm{THF}$ at 50 ${ }^{\circ} \mathrm{C}$ for $32 \mathrm{~h}$ to provide the targeted cajaninstilbenes acid 6 analogues 15a-151 in good to excellent yields (76-90\%) (Scheme 2). The results are summarized in Table 1. The ability

Table 1. Cajaninstilbenes Acid and Its Analogues

\begin{tabular}{|c|c|c|c|}
\hline s.n. & $\operatorname{Ar} 13 a-m$ & $14 a-m^{a}$ (yield) & $15 \mathbf{a}-\mathbf{m}^{a}$ (yield) \\
\hline 1 & 13a $\left(\mathrm{C}_{6} \mathrm{H}_{5}\right)$ & 14a $(83 \%)$ & 15a $(90 \%)$ \\
\hline 2 & $13 \mathbf{b}\left(4-\mathrm{MeOC}_{6} \mathrm{H}_{4}\right)$ & 14b (74\%) & $\mathbf{1 5 b}(81 \%)$ \\
\hline 3 & $13 \mathrm{c}\left(3,5-\mathrm{MeO}_{2} \mathrm{C}_{6} \mathrm{H}_{3}\right)$ & $14 \mathrm{c}(77 \%)$ & $15 c(88 \%)$ \\
\hline 4 & 13d $\left(3,4,5-\mathrm{MeO}_{3} \mathrm{C}_{6} \mathrm{H}_{2}\right)$ & 14d (80\%) & $15 d(85 \%)$ \\
\hline 5 & $13 \mathrm{e}\left(2,3,4-\mathrm{MeO}_{3} \mathrm{C}_{6} \mathrm{H}_{2}\right)$ & $14 e(83 \%)$ & $15 e(85 \%)$ \\
\hline 6 & $13 \mathrm{f}\left(3,4-\mathrm{OCH}_{2} \mathrm{OC}_{6} \mathrm{H}_{3}\right)$ & $14 f(65 \%)$ & $15 f(88 \%)$ \\
\hline 7 & $13 \mathrm{~g}\left(4-\mathrm{FC}_{6} \mathrm{H}_{4}\right)$ & $14 \mathrm{~g}(62 \%)$ & $15 \mathrm{~g}(80 \%)$ \\
\hline 8 & 13h $\left(2,4-\mathrm{F}_{2} \mathrm{C}_{6} \mathrm{H}_{3}\right)$ & 14h $(76 \%)$ & 15h $(87 \%)$ \\
\hline 9 & $13 \mathbf{i}\left(3,4-\mathrm{Cl}_{2} \mathrm{C}_{6} \mathrm{H}_{3}\right)$ & $14 \mathrm{i}(76 \%)$ & $15 \mathbf{i}(81 \%)$ \\
\hline 10 & 13j (2-pyridyl) & $\mathbf{1 4 j}(77 \%)$ & $15 \mathbf{j}(76 \%)$ \\
\hline 11 & 13k (3-pyridyl) & $14 k(65 \%)$ & $15 k(88 \%)$ \\
\hline 12 & 131 (4-pyridyl) & $141(80 \%)$ & $151(83 \%)$ \\
\hline 13 & $13 \mathrm{~m}(6 \text {-pyronyl })^{b}$ & $14 m(74 \%)$ & $15 \mathrm{~m}(84 \%)$ \\
\hline
\end{tabular}

${ }^{a}$ Yield of products after column chromatography. ${ }^{b}$ Precisely: (4-methoxy-2H-pyran-2-one)-6-yl.

of sulfone 4 to olefinate aldehydes was not restricted to aromatic aldehydes alone. The pyrone based aldehyde $13 \mathrm{~m},{ }^{23}$ as an illustrative example (entry 13, Table 1), could be used to generate the corresponding product $14 \mathrm{~m}$ in equally good yields (74\%). By anticipating the pyrone moiety to be incompatible with the hydrolytic conditions, selective removal of acetyl protection in $14 \mathrm{~m}$ was achieved with $\mathrm{K}_{2} \mathrm{CO}_{3}$ in $\mathrm{MeOH}$ and the product $15 \mathrm{~m}$ with methyl ester was obtained in good yields (84\%), thereby illustrating the usefulness of the synthetic route. The use of aqueous $\mathrm{NaOH}$ solution on $14 \mathrm{~m}$, for hydrolysis, indeed leads to extensive degradation of the compound.

Having successfully achieved synthesis of highly functionalized $C$-prenylated stilbene derivatives $15 \mathbf{a}-\mathbf{m}$, the utility of the building block 4 was now explored toward the synthesis of 
targeted bibenzyl compounds 5, i.e. amorfrutin A and its analogues. To our delight, in a model reaction, sulfone 4 underwent clean benzylation at the benzylic site, through the generation of the carbanion with sodium hydride as the base, and with benzyl bromide $16 \mathrm{a}$ as the electrophile, at $0{ }^{\circ} \mathrm{C}$ to room temperature, in 3 to $4 \mathrm{~h}$.

The desired monobenzylated product $17 \mathbf{a}$ was obtained in good yield (78\%). This procedure was generalized with various other substituted benzyl bromides $16 \mathbf{b}-\mathbf{i}$ for alkylation with building block 4. Desired monobenzylated products $17 \mathbf{b}-\mathbf{i}$ were obtained in good to excellent yields (69-95\%) (Scheme 3).

Scheme 3. Synthesis of Amorfrutin A (19a) and Its Analogues $(19 b-i)$

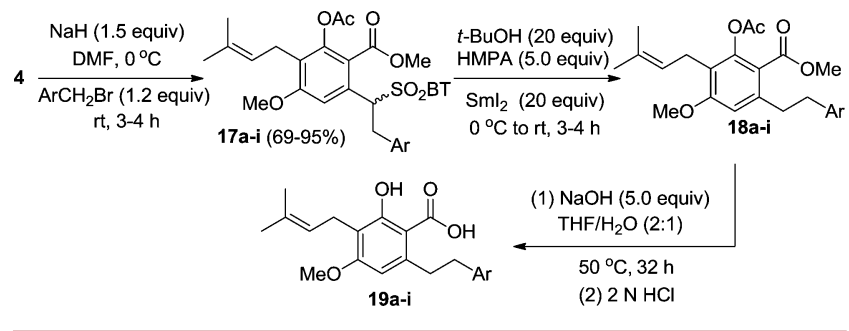

The monobenzylated compounds $17 \mathbf{a}-\mathbf{i}$ were subjected to desulfonylation with inexpensive reagents such as sodium amalgam $(10 \%)$ in methanol ${ }^{24}$ or $\mathrm{Mg} / \mathrm{AcOH} / \mathrm{AcONa}$ in $\mathrm{DMF}^{25}$ Under both conditions, desulfonylation resulted in a complex reaction mixture as reflected by multiple spots on TLC. The use of $\mathrm{SmI}_{2}(0.1 \mathrm{M})$ solution in $\mathrm{THF}^{25}$ along with HMPA (5 equiv) and $t$-BuOH (20 equiv) at $0{ }^{\circ} \mathrm{C}$ to room temperature, enabled clean desulfonylation and resulted in the formation of products $18 \mathbf{a}-\mathbf{i}$ in moderate to good yields (see Table 2). Finally, hydrolysis of these compounds 18a-i provided the targeted amorfrutin A 19a and its analogues $19 b-\mathbf{i}$ in good to excellent yields $(73-90 \%)$.

Table 2. Amorfrutin A (19a) and Its Analogues (19b-i)

\begin{tabular}{|c|c|c|c|}
\hline s.n. & $\operatorname{Ar} 16 a-j$ & $18 a-i(\text { yield })^{a}$ & $19 a-i(\text { yield })^{c}$ \\
\hline 1 & $16 \mathrm{a}\left(\mathrm{C}_{6} \mathrm{H}_{5}\right)$ & $18 a(76 \%)$ & 19a $(73 \%)$ \\
\hline 2 & $\mathbf{1 6 b}\left(4-\mathrm{MeOC}_{6} \mathrm{H}_{4}\right)$ & $18 b(63 \%)$ & $19 b(90 \%)$ \\
\hline 3 & $16 \mathrm{c}\left(3,5-\mathrm{MeO}_{2} \mathrm{C}_{6} \mathrm{H}_{3}\right)$ & $18 \mathrm{c}(83 \%)$ & $19 c(85 \%)$ \\
\hline 4 & 16d $\left(3,4,5-\mathrm{MeO}_{3} \mathrm{C}_{6} \mathrm{H}_{2}\right)$ & $18 d(64 \%)$ & 19d $(84 \%)$ \\
\hline 5 & $16 \mathrm{e}\left(2,3,4-\mathrm{MeO}_{3} \mathrm{C}_{6} \mathrm{H}_{2}\right)$ & $18 \mathrm{e}(71 \%)$ & $19 \mathrm{e}(88 \%)$ \\
\hline 6 & $16 f\left(3,4-\mathrm{OCH}_{2} \mathrm{OC}_{6} \mathrm{H}_{3}\right)$ & $18 f(66 \%)$ & $19 f(85 \%)$ \\
\hline 7 & $16 \mathrm{~g}\left(4-\mathrm{FC}_{6} \mathrm{H}_{4}\right)$ & $18 \mathrm{~g}(88 \%)$ & $19 \mathrm{~g}(83 \%)$ \\
\hline 8 & $16 \mathbf{h}\left(2,4-\mathrm{F}_{2} \mathrm{C}_{6} \mathrm{H}_{3}\right)$ & $18 \mathrm{~h}(88 \%)$ & $19 \mathrm{~h}(85 \%)$ \\
\hline 9 & 16i $\left(3,4-\mathrm{Cl}_{2} \mathrm{C}_{6} \mathrm{H}_{3}\right)$ & $18 \mathrm{i}(78 \%)$ & $19 \mathrm{i}(90 \%)$ \\
\hline
\end{tabular}

To determine binding of the synthesized compounds to PPARs, we performed in vitro competitive binding studies with all three PPAR subtypes namely $\operatorname{PPAR} \alpha, \beta / \delta$, and $\gamma$. In general, for $\operatorname{PPAR} \alpha$, the compounds revealed binding affinity constants $\left(K_{\mathrm{i}}\right)$ in the low micromolar range, except for $\mathbf{1 5 f}$ that showed a $K_{\mathrm{i}}$ value of $558 \mathrm{nM}$ (Supporting Information 2, Supplementary Figure $1 \mathrm{a}-\mathrm{c}$ and Supplementary Table 1$)$. For $\operatorname{PPAR} \beta / \delta$, the compounds also featured $K_{\mathrm{i}}$ values in the low micromolar range, except for 15f, 19a, 19f, and $19 \mathrm{~g}$, which showed a $K_{\mathrm{i}}$ value of $569,915,462$, and $754 \mathrm{nM}$, respectively. Strikingly, for $\operatorname{PPAR} \gamma$ many of the compounds showed high binding affinities in the nanomolar range (Supporting Information 2, Supplementary Table 1), in particular for cajaninstilbene acid derivative $\mathbf{1 5 f}$ we observed a $K_{\mathrm{i}}$ value of $30 \mathrm{nM}$. As recently described for the naturally occurring amorfrutin $\mathrm{A}$, also the synthesized compounds induced efficient dissociation of NCoR from PPAR $\gamma$ up to for example $72 \%$ for $\mathbf{1 5 f}$ compared to rosiglitazone. Inhibitory concentrations (IC50) of $20 \mathrm{nM}$ could be detected for this compound (Supporting Information 2, Supplementary Figure 1d and Table 2).

In summary, the first library of synthetic analogues of natural amorfrutins produced in our synthetic endeavor contains a number of promising binders of PPARs and efficient inhibitors of NCoR. ${ }^{26}$ Notably, none of the compounds showed relevant induction of toxic effects (Supporting Information 2, Supplementary Table 3 and Supplementary Figure 2).

In conclusion, the here presented common building block 4 has enabled convenient access to initial libraries of synthetic analogues ${ }^{18}$ of recently described antidiabetic amorfrutins ${ }^{5,8}$ and cajaninstilbene acids. The synthetic analogues reported herein point to promising prospects of amorfrutins and cajaninstilbene acids toward biomedical applications. Relevant applications may include development of drug candidates with improved safety profiles and provision of new chemical tools for mechanistic PPAR research.

\section{ASSOCIATED CONTENT}

\section{Supporting Information}

Experimental details and further results are available as Supporting Information 1 and 2 . This material is available free of charge via the Internet at http://pubs.acs.org.

\section{AUTHOR INFORMATION}

\section{Corresponding Authors}

*E-mail: isingh@iitm.ac.in.

*E-mail: sauer@molgen.mpg.de.

\section{Author Contributions}

All authors contributed equally to this work.

Notes

The authors declare no competing financial interest.

\section{ACKNOWLEDGMENTS}

I.S.A. thanks BRNS for the project and IIT-M for infrastructure. R.M. thanks CSIR for an SRF award. S.S. was supported by the BMBF (Grant Number 0315082 (01EA1303)). We thank Dr. Florenz Sasse and Aman Bhasin (both at Department of Chemical Biology, Helmholtz Centre for Infection Research, Germany) for support and discussions.

\section{DEDICATION}

Dedicated to Professor Richard R. Schmidt on the occasion of his 80th birthday.

\section{REFERENCES}

(1) (a) Evans, R. M.; Barish, G. D.; Wang, Y. Z. Nat. Med. 2004, 10, 355-361. (b) Lazar, M. A. Biochimie 2005, 87, 9-13.

(2) (a) Holzhauser, S.; Freiwald, A.; Weise, C.; Multhaup, G.; Han, C. T.; Sauer, S. Angew. Chem., Int. Ed. 2013, 52, 5171-5174.

(b) Bannister, A. J.; Kouzarides, T. Cell Res. 2011, 21, 381-395.

(3) Moller, D. E. Nature 2001, 414, 821-827.

(4) Mitscher, L. A.; Park, Y. H.; Alshamma, A.; Hudson, P. B.; Haas, T. Phytochemistry 1981, 20, 781-785. 
(5) Weidner, C.; de Groot, J. C.; Prasad, A.; Freiwald, A.; Quedenau, C.; Kliem, M.; Witzke, A.; Kodelja, V.; Han, C. T.; Giegold, S.; Baumann, M.; Klebl, B.; Siems, K.; Muller-Kuhrt, L.; Schurmann, A.; Schuler, R.; Pfeiffer, A. F.; Schroeder, F. C.; Bussow, K.; Sauer, S. Proc. Natl. Acad. Sci. U.S.A. 2012, 109, 7257-7262.

(6) (a) Weidner, C.; Wowro, S. J.; Freiwald, A.; Kawamoto, K.; Witzke, A.; Kliem, M.; Siems, K.; Muller-Kuhrt, L.; Schroeder, F. C.; Sauer, S. Diabetologia 2013, 56, 1802-1812. (b) Sauer, S.; Weidner, C.; Kliem, M.; Schroeder, F. C.; Micikas, R. J. Patent Pending-PCT Int. Appl. (2014), WO 2014177593 A1 20141106. (c) de Groot, J. C.; Weidner, C.; Krausze, J.; Kawamoto, K.; Schroeder, F. C.; Sauer, S.; Büssow, K. J. Med. Chem. 2013, 56, 1535-1543.

(7) Li, P.; Fan, W.; Xu, J.; Lu, M.; Yamamoto, H.; Auwerx, J.; Sears, D. D.; Talukdar, S.; Oh, D.; Chen, A.; Bandyopadhyay, G.; Scadeng, M.; Ofrecio, J. M.; Nalbandian, S.; Olefsky, J. M. Cell 2011, 147, 815826.

(8) Sauer, S. ChemBioChem 2014, 15, 1231-1238.

(9) Shen, T.; Wang, X.-N.; Lou, H.-X. Nat. Prod. Rep. 2009, 26, 916935.

(10) Zhao, J.; Fu, Y.; Luo, M.; Zu, Y.; Wang, W.; Zhao, C.; Gu, C. J. Agric. Food Chem. 2012, 60, 4314-4319.

(11) Wu, N.; Fu, K.; Fu, Y.-J.; Zu, Y.-G.; Chang, F.-R.; Chen, Y.-H.; Liu, X.-L.; Kong, Y.; Liu, W.; Gu, C.-B. Molecules 2009, 14, 10321043.

(12) (a) Crombie, L.; Jamieson, S. V. J. Chem. Soc., Perkin Trans. 1 1982, 1467-1475. (b) Eicher, T.; Tiefensee, K.; Donig, R.; Pick, R. Synthesis-Stuttgart 1991, 98-102. (c) Park, B. H.; Lee, Y. R.; Kim, S. H. Bull. Korean Chem. Soc. 2011, 32, 566-570.

(13) (a) Zinsmeister, H. D.; Becker, H.; Eicher, T. Angew. Chem., Int. Ed. Engl. 1991, 30, 130-147. (b) Schwaben, J.; Cordes, J.; Harms, K.; Koert, U. Synthesis 2011, 2929-2934.

(14) (a) Laclef, S.; Anderson, K.; White, A. J. P.; Barrett, A. G. M. Tetrahedron Lett. 2012, 53, 225-227. (b) Cordes, J.; Laclef, S.; White, A. J. P.; Barrett, A. G. M. J. Org. Chem. 2012, 77, 3524-3530.

(15) Song, Y. Y.; He, H. G.; Li, Y.; Deng, Y. Tetrahedron Lett. 2013, 54, 2658-2660.

(16) (a) Ji, X.-Y.; Xue, S.-T.; Zheng, G.-H.; Han, Y.-X.; Liu, Z.-Y; Jiang, J.-D.; Li, Z.-R. Acta Pharm. Sinica B 2011, 1, 93-99.

(17) Mitra, P.; Shome, B.; Ranjan De, S.; Sarkar, A.; Mal, D. Org. Biomol. Chem. 2012, 10, 2742-2752.

(18) Aidhen, I. S.; Mukkamala, R. Indian Patent Application No:

5457/CHE/2013.

(19) Mal, D.; De, S. R. Org. Lett. 2009, 11, 4398-4401.

(20) Fürstner, A.; Gastner, T. Org. Lett. 2000, 2, 2467-2470.

(21) Dintzner, M. R.; Morse, K. M.; McClelland, K. M.; Coligado, D. M. Tetrahedron Lett. 2004, 45, 79-81.

(22) CCDC 1013467; see the Supporting Information for details.

(23) Fang, Z.; Liao, P.-C.; Yang, Y.-L.; Yang, F.-L.; Chen, Y.-L.; Lam, Y.; Hua, K.-F.; Wu, S.-H. J. Med. Chem. 2010, 53, 7967-7978.

(24) Mauleón, P.; Núñez, A. A.; Alonso, I.; Carretero, J. C. Chem.Eur. J. 2003, 9, 1511-1520.

(25) Jiang, L.; Lei, Q.; Huang, X.; Cui, H.-L.; Zhou, X.; Chen, Y.-C. Chem.-Eur. J. 2011, 17, 9489-9493.

(26) Auwerx, J. Diabetologia 1999, 42, 1033-1049. 